NOT FOR QUOTATION

WITHOUT PERMISSION

OF THE AUTHOR

\title{
ESTMATION OF THE REQUIRED AMOUNT OF
}

HYDROLOGICAL EXPLORATION IN LIGNTTE UINING AREAS

ON THE BASIS OF HYPOTHETICAL HYDROGEOLOGICAL MODELS

\author{
S. Kaden \\ F. Relchel \\ L. Luckner \\ December 1985 \\ CP-85-47
}

Collaborative Papers report work which has not been performed solely at the International Institute for Applied Systems Analysis and which has recetved only limited review. Views or opinions expressed herein do not necessarlly represent those of the Institute, its National Member Organizations, or other organtzations supporting the work.

INTERNATIONAL INSTITUTE FOR APPLIED SYSTEMS ANALYSIS 2361 Laxenburg, Austria 



\section{PREFACE}

The Regional Water Policies project of IIASA focuses on intensively developed regions where above all groundwater is the integrating element of the environment. Our research is directed towards the development of methods and models to support the resolution of conflicts within such socioeconomic environmental systems. Complex decision support model systems are under development for a region with intense agriculture in The Netherlands and for an open-pit lignite mining area in the GDR. In both cases the modeling of the groundwater resources system is of fundamental importance. Up to now it has been assumed that the groundwater resources system is explored in detail and all data needed for policy analysis are available with sufficient accuracy.

Generally this assumption is not fulfilled due to the limits of exploration. Hydrogeological exploration, above all based on exploration drillings resulting in point samples only, is a very costly task. Consequently hydrogeological parameters can be explored with certain precision only, depending on the number of exploration drillings. For any decision being based on these parameters this uncertainty has to be taken into the account. Usually it comes to "pessimistic" decisions or with other words to an "overdimensioning" of the cotrol units of the system under study. A compromize has to be fund between the amount of exploration (its precision) and the econmic losses due to "pessimistic" decisions.

This paper describes an attemp to solve such problems with special regard to lignite mining areas. For the future the extension of this approach and its inclusion into complex decision support systems becomes realistic.

Sergei Orlovski Project Leader Regional Water Policies Project 


\section{ABSTRACT}

Mine drainage is a necessary but very costly precaution for open-pit lignite mining in sandy aquifers. Consequently, the minimization of the number of drainage wells and their optimal operation become important tasks in designing mine drainage systems. Comprehensive groundwater flow models have to be used, both, for the design of drainage wells, and for the analysis of water management strategies in mining areas. The accuracy of computations with such models depends on the precision of the underlying hydrogeological informations. In order to get these informations detailed and costly hydrogeological explorations have to be done in the mining regions.

The basic informations are obtained using exploration drilling. The cost for hydrogeological exploration are approximately a linear function of the number of exploration hore holes. Therefore the reduction of drilling gets a key role in reducing costs of exploration. This might be done by:

- increased use of geophysical exploration methods,

- complex analysis of exploration results using mathematical statistical methods,

- precise estimation of the required amount of hydrogeological informations.

The paper describes a mathematical approach to support the complex decision making procedure of estimating the optimal amount of hydrogeological exploration with respect to a given mine drainage goal. 


\section{CONTENTS}

1. Introcuction 1

2. Nethodological Approach 4

2.1 Hydrogeological Schematization and Parameter Model 4

2.2 Design of the Drainage System 8

2.3 Geohydrological Calculation with Hypothetical Models 9

2.4 Economic Evaluation Depending on Exploration Precision 11

2.5 Optimal Exploration Precision 15

3. Test Example 16

4. Concluding Remarks 22

References 23 



\title{
ESTMMATION OF THE REQUIRED AMOUNT OF HYDROLOGICAL EXPLORATION IN LIGNITE MINING AREAS ON THE BASIS OF HYPOTHETICAL HYDROGEOLOGICAL MODELS
}

\author{
S. Kaden ${ }^{1}$, F. Reichel ${ }^{2}$ and L. Luckner ${ }^{2}$
}

\section{Introdnction}

For 1985 in the German Democratic Republic (GDR) an annual lignite production of 300 Mill.tons/anrum is planned. The principal mining technology is open-pit mining. The lignite seams are embedded in quarternary/tertiary aquifer systems. These aquifer systems have to be drained to satisfy the geomechanical stability of the slopes of the open-pit mines. In 1984 about 1.7 Bill. $m^{3}$ mine drainage water has been pumped out, operating more then 7000 drainage wells. Therefore, approximately $17 \mathrm{z}$ of the total mining cost are required, Reisner and Rösch 1984.

Consequently, the minimization of the number of drainage wells and their optimal operation become important tasks in designing mine drainage systems.

The extensive mine drainage causes manifold impacts on the water resources in mining areas and significant conflicts between different water users, Kaden et al. 1985. Groundwater flow models have to be used, both, for the design of drainage wells, and for the analysis of water management strategies in mining areas, Kaden and Luckner 1984.

The accuracy of computations with comprehensive groundwater flow models depends on the precision of the underlying hydrogeological informations. In order to get these informations detalled and costly hydrogeological explorations have to be done.

\footnotetext{
1) 1nternational Institute for Applied Systems Analysis, Laxenburg, Austria

2) Research Group for Open-Pit Dewatering Problems of the Grossraschen Institute for Lignite MinIng and the Dresden University of Technology
} 
Generally, hydrogeological exploration is based on the following techniques:

- exploration drilling for exploration including the collection and analysis of samples of the material in the bore hole, resulting in point informations on the hydrogeological structure,

- pumping tests for the estimation of transmissivities and specific yields being representative for a small region of the aquifer (a few $100 \mathrm{~m}^{2}$ ).

- geophysical methods to get detalled informations within bore holes, and above all using surface methods and remote sensing techniques in order to obtain local and regional informations on the geohydrological system.

In Figure 1 the outcome of these different methods is illustrated.

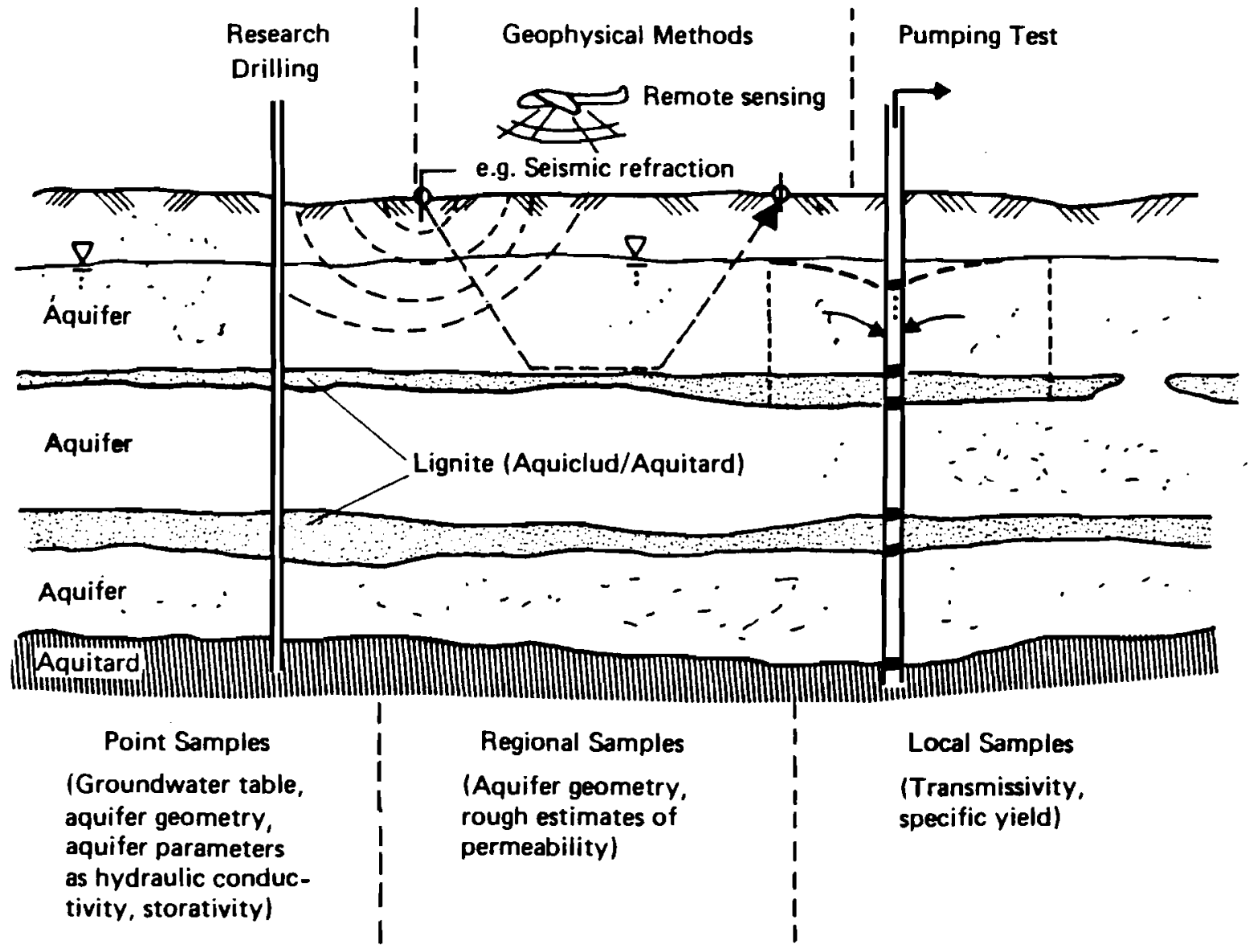

Figure 1: Methods for hydrogeological exploration

The basic informations are oblained using exploration drilling. The cost for hydrogeological exploration are approximately a linear function of the number of exploration bore holes. Therefore, the reduction of drilling gets a key role in reducing cost of exploration. This might be done by:

- increased use of geophysical exploration methods,

- complex analysis of exploration results using mathematical statistical methods, 
- precise estimation of the required amount of hydrogeological informations.

In the paper we will concentrate on the last mentioned alternative.

At present, in the GDR the following tools are used for the estimation of the required amount of hydrogeological exploration:

a) standard values in the field of lignite exploration according to several stages of exploration and according to the type of the coal seam and deposit, n.n. 1976 , see Figure 2a.

b) catalogue of groundwater deposits, Bamberg et al. 1975; the parameters of the deposits are characterized by statistical values (mean, dispersion, variance). Assuming a required precision of exploration, the required amount of exploration can be estimated, see Figure $2 b$.

\begin{tabular}{|c|c|c|c|c|}
\hline & Exploration & $\begin{array}{l}\text { Formation of the } \\
\text { Hydrogeologic Model }\end{array}$ & $\begin{array}{l}\text { Simulation } \\
\text { and Design }\end{array}$ & Economic Evaluation \\
\hline a) & \multirow{3}{*}{$\begin{array}{l}\text { Distance between } \\
\text { bore holes }\end{array}$} & \multirow{3}{*}{$\begin{array}{l}\text { Geologic bassic model: } \\
\text { Type of deposit } \\
\text { Type of coal seam }\end{array}$} & & \multirow{2}{*}{$\begin{array}{l}\text { Estimation of the benefit } \\
\text { of exploration: } \\
\text { Stages of exploration }\end{array}$} \\
\hline \multirow{3}{*}{ 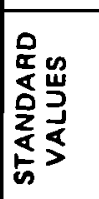 } & & & & \\
\hline & & & & \\
\hline & Number of bore & & & \\
\hline & & & & \\
\hline b) & & Hydrogeologic besic model: & & Estimation of the influence \\
\hline & & Type of ground water deposit & & $\begin{array}{l}\text { of the precision of } \\
\text { exploration on }\end{array}$ \\
\hline 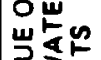 & $\begin{array}{l}\text { Required precision } \\
\text { of exploration }\end{array}$ & & & draingge design \\
\hline 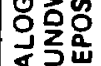 & $\begin{array}{l}\text { Distance between. } \\
\text { bore holes }\end{array}$ & & & \\
\hline に曷口 & Number of bore & & & \\
\hline c) & & & & Estimation of: \\
\hline . & & Hydrogeologic besic model & Rough design & Cost of investment \\
\hline 台电 & . & & & $\begin{array}{l}\text { Losses due to insufficient } \\
\text { mine drainage }\end{array}$ \\
\hline$\frac{0}{\frac{5}{0}}$ & & & & $\begin{array}{l}\text { Benefits due to earlier } \\
\text { operation of mine drainage }\end{array}$ \\
\hline 出 & Number of bore & & & Cost of exploration \\
\hline
\end{tabular}

Figure 2: Methods for the estimation of the required amount of hydrogeological exploration in the GDR

Both the tools give only rough estimates and they do not consider the aim of exploration, its role in the complex economic system of exploration - mine drainage - mining. Principally, the amount of exploration is estimated by experts taking into the account this complexity, but more or less on a subjective basis, see Figure 2c. 
Obviously, the objectives to minimize mine drainage cost (e.g. minimizing the number of drainage wells) and to minimize exploration cost (e.g. minimizing the number of exploration drillings) are contradictory. - The less hydrogeological exploration is done, the more uncertain are the hydrogeological parameters for drainage well design.

In the case of uncertain parameters drainage wells are more or less overdimensioned or the risk of geomechanical averages increases. Nevertheless, detailed hydrogeological exploration may be omitted if the risk of averages (and its economic consequences) is small in comparison with the benefits of saved exploration capacity and earlier operation of the drainage system, Goldbecher et al. 1982 .

In the following we propose a mathematical approach to support the complex decision making procedure of estimating the amount of hydrogeological exploration, see also Reichel and Lomakin 1984.

\section{Methodological Approach}

Hydrogeological exploration in lignite mining areas alms above all at the estimation of hydrogeological parameters for calculations of the groundwater flow caused by mine drainage in the aquifer system. Such calculations include:

- estimation of flow to dewatering wells as the basis of mine drainage design,

- estimation of the total discharge of the mine drainage system for the design of mine water treatments plants, and for water management decisions,

- estimation of groundwater table variations (both, lowering in drained areas, and rise in abandoned mining areas) for water management and environmental decisions.

Generally, the installation and operation of mine drainage systems becomes the most costly task for water related decisions in mining areas. For the design of mine drainage systems the most detailed hydrogeological informations, their highest accuracy is needed. Consequently it is reasonable to assume, that the amount of hydrogeological exploration is estimated depending on the required exploration for the design of the mine drainage system. For an extention see Section 4.

Our approach is based on the following principal presumptions:

- For the area under consideration tentative geological and hydrogeological investigations have been done including preliminary (rough) exploration.

- The objectives of drainage are defined (location and depth of the lignite mine) and the drainage system is drafted (type of the drainage system, its depth and location).

The working steps of the proposed approach are summerized in Figure 3.

\subsection{Hydrogeological Schematization and Parameter Model}

The complicated and partly random structure of hydrogeolocial systems necessitates their schematization because:

- hydrogeological exploration results either in rough estimates of the structure (geophysical methods) or in random samples (drilling, pumping tests),

- calculations of the groundwater flow system require a schematized and more or less simplified hydrogeolocial model of the real system. 


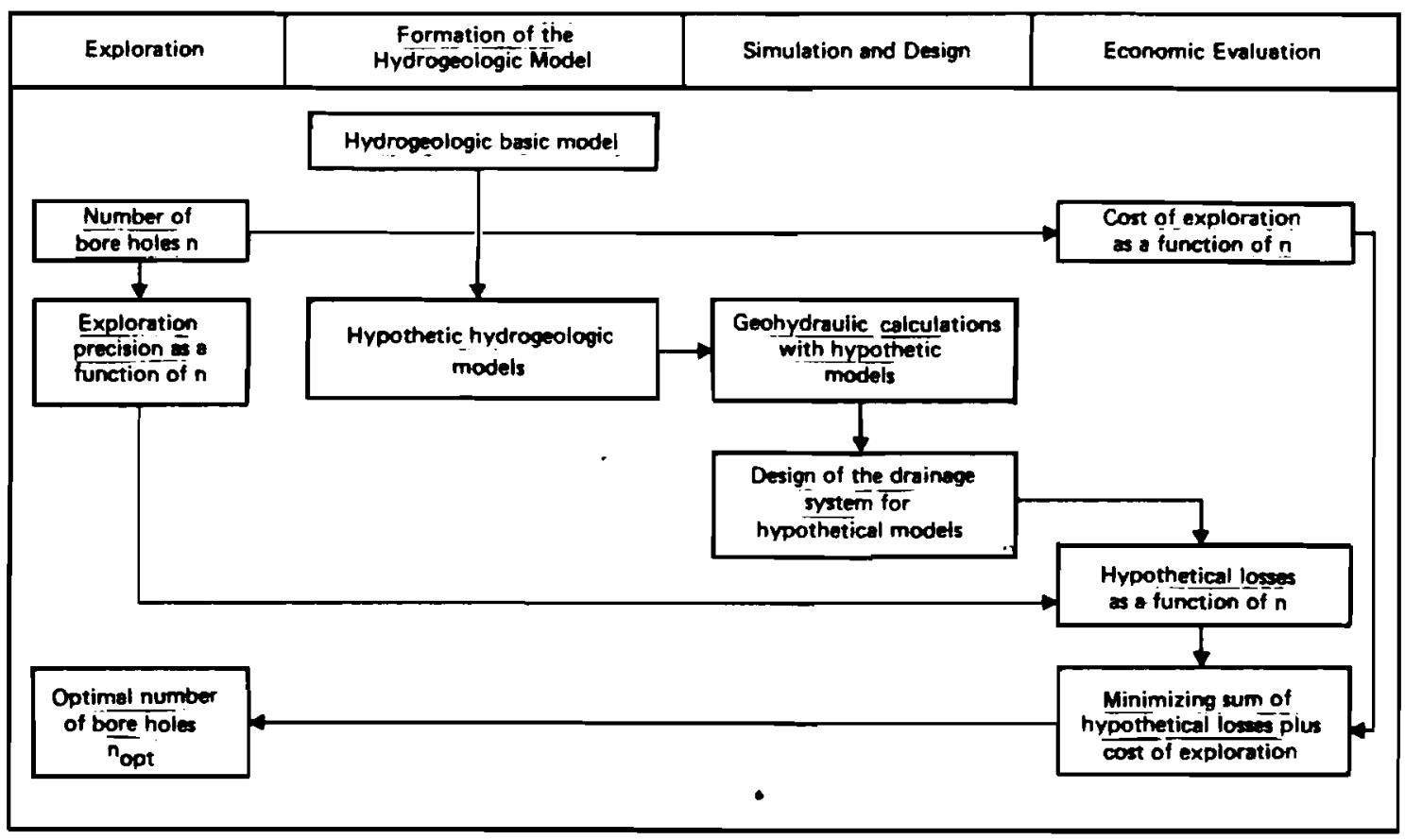

Figure 3 : Working steps

Let us assume that the principle vertical structure (stratification) of the hydrogeological system under study is known. Usually this knowledge is well based on general geological informations and preliminary explorations. From that we obtain a vertical schematization. Define $P=\left(p^{(1)}, p^{(2)}, \cdots\right)^{T}$ the set of hydrogeological parameters needed to quantify this schematization. The horizontal parameter distribution is called parameter function $f_{P}(x, y)$.

In the course of hydrogeological exploration (exploration drilling) point samples of the parameter function are obtained.

$$
P\left(x_{j}, y_{j}\right)=f_{P}\left(x_{j}, y_{j}\right), j=1, \ldots, n_{b}
$$

with $n_{b}$ - number of bore holes

Based on these point samples an approximative parameter function has to be estimated.

$$
\tilde{\mathbf{P}}=\tilde{\mathbf{f}}_{P}(\boldsymbol{x}, y) \approx \tilde{f}_{P}(x, y)
$$

This is a widely studied and discussed problem in hydrogeological research and practice. From our point of view only two concepts are practically important:

- the kriging interpolation technique of best linear unbiased estimation of a regionalized variable, for a review see Virdee and Kottegoda 1984,

- the concept of geohydraulically representative parameters.

The kriging interpolation technique and others are used to estimate locel parameters, whereas the second concept results in regional representative parameters. Our approach is based on the second concept. 
The area under consideration $\Sigma$ (area being influenced by the mining) should be divided into $N$ subareas $\Delta \Sigma_{i}$.

$$
\Sigma=\Sigma_{1} \cup \Sigma_{2} \cup \cdots \cup \Sigma_{N}
$$

Each subarea is characterized by a uniform stratification and an accompanying set of hydrogeological parameters.

For the purpose of simplification we consider in the following only one parameter $p_{\mathfrak{l}}$ for each subarea $i$, being the decisive parameter for drainage design. The approach can be extended for several parameters without principle difficulties.

$$
p_{i}=p_{i}(x, y) \quad(x, y) \varepsilon \Delta \Sigma_{i}, i=1, \ldots, N
$$

The parameter distribution within the subarea is assumed to be random, and the subarea should appertain statistically to a basic totallity with regard to the $p_{i}$ feature.

The results of hydrogeological explorations are used to estimate empirical distribution functions of the parameter $p_{i}$. E.g. statistical investigations of the empirical distribution functions of the hydraulic conductivity for a large number of aquifers and subareas have revealed different distributions ranging from the Normal distribution to a logarithmic bell-shaped distribution, Beims 1974 .

For geohydraulic calculations, the random parameter $p_{\mathfrak{q}}$ has to be replaced by a constant geohydraulically representative parameter $p_{R, 4}$.

According to Beims and Luckner 1975 , the parameter $p_{R, t}$ is geohydraulically representative, if computations of the flow system (aimed at the design of the drainage system) with the representative value are adequate to computations with the real hydrogeological parameter $p_{i}(x, y)$ as a function in space. This means, the real hydrogeological system in the subarea is replaced by a schematized horizontal stratified subarea being homogeneously within each stratum, see Figure 4.

Frequently, as an estimate of the geohydraulically representative value the arithmetic mean $\bar{p}_{i}$ from all samples in the subarea is used, assuming normal distributed parameters. For the parameter holds:

$$
p_{i}: N\left(\bar{p}_{\mathfrak{i}}, \sigma_{i}\right)
$$

We need an estimate $\tilde{p}_{\mathfrak{q}}$ of the mean. Because $\tilde{p}_{\mathfrak{q}}$ is normal distributed, the estimate of the mean will be normal distributed:

$$
\tilde{p}_{i}: N\left(\bar{p}_{i}, \frac{\sigma_{i}}{\sqrt{n_{b, i}}}\right)
$$

with $\quad \sigma_{\imath}$ - variance

$n_{b, 6}-$ number of samples (bore holes).

Under the given assumptions a confidence interval may be estimated as defined below.

$$
\bar{p}_{i}-\frac{s_{i}}{\sqrt{n_{b, i}}} \cdot t_{a, m_{i}}<\tilde{p}_{i}<\bar{p}_{i}+\frac{s_{i}}{\sqrt{n_{b, b}}} \cdot t_{a, m_{i}}
$$

with a - error probability

$t_{a, m_{i}}$-parameter of the t-distribution for unilateral questioning

$m_{i}$ - degrees of freedom $=n_{t, 1}-1$ 


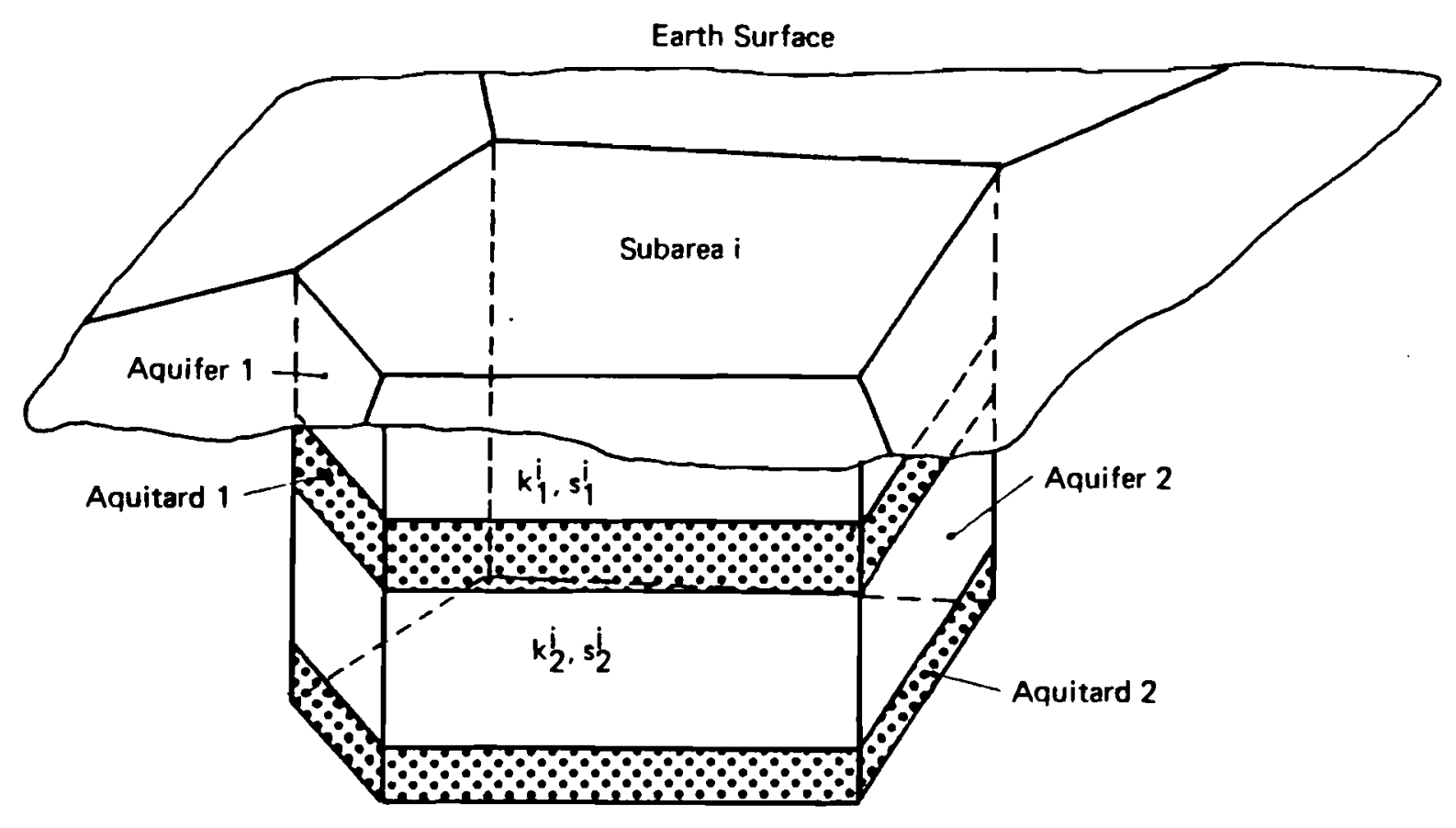

k: hydraulic conductivity

s: storativity

Figure 4: Schematized hydrogeological structure of subareas

$s_{\mathfrak{1}}$ - estimate of the variance.

A generalized method for the estimation of geohydraulically representative parameters (hydraulic conductivity, transmissivity) has been developed by Beims, 1974. The method although renders the estimation of the confidence of the calculated parameters. For the geohydraulically representative parameters holds:

$$
p_{R, \delta}=\bar{p}_{i} \cdot c\left(v_{t}, x\right)
$$

and for the confidence limits we obtain:

$$
p_{R, b}-\frac{s_{i}}{\sqrt{n_{b, 1}}} \cdot t_{a, m_{i}} \cdot c<\tilde{p}_{i}<p_{R, 1}+\frac{s_{i}}{\sqrt{n_{b, b}}} \cdot t_{a, m_{i}} \cdot c
$$

with $\quad c$-reduction factor

$v \quad$ - variation coefficient

$\boldsymbol{x}$ - transformation coefficient

Both the simple arithmetic mean and more sophisticated parameter models for geohydraulically representative parameters open the possibility of confidence estimates.

$$
p_{R, 8}-\Delta p_{R, 8}\left(n_{b, 8}\right) \leq \tilde{p}_{1} \leq p_{R, 1}+\Delta p_{R, 3}\left(n_{b, 8}^{\prime}\right)
$$


With Eq. (8) we have a relationship between:

- the exploration precision in terms of the confidence of the hydrogeological parameter to be explored and

- the amount of exploration in terms of the number of exploration drillings.

Generally, the parameter model has to be chosen depending on the goal of exploration and on the expected hydrogeological situation. Other comprehensive parameter models (with autocorrelation) are proposed by Bamberg et al. 1975, and Stoyan 1973, 1974.

**** Es ist zu pruefen, ob diese Modelle sich in das vorgeschlagene Konzept einordnen lassen, Darstellung ggf. ausfuehrlicher oder ganz weglassen.

\subsection{Design of the Drainage System}

The common technology for mine drainage in sandy aquifers are vertical dewatering wells (border and field well galleries). In general their design is based on uncertain data due to the random structure of the hydrogeological system and its restricted explorability. Furthermore, errors caused by schematizations and numerical calculations have to be taken into the account.

In open-pit mining the economic losses due to insufficient mine drainage (causing water inrushes) may be tremendous and may exceed the losses resulting from "over-design". The lower the risk of a breakdown of mine drainage the higher is the risk of uneconomic design. Nevertheless, the risk of damages due to "underdesign" should be sufficiently small.

Principally, the system of dewatering wells has to be designed in such a way that the technologically required groundwater depression within the mine will be satisfied with a certain reliability. Hence, the design depend on the reliability of the input data.

According to our principal presumptions we assume a fixed construction of drainage wells (drilling diameter, well screen and filter, capacity of pumps), as well as a given location of the dewatering galleries. Based on that, the number of wells, their distribution along the galleries become the decisive design values. These values depend strongly on the specific groundwater flow to the well gallery, the specific pumpage respectively, for a given groundwater depression target.

For the purpose of simplification the drainage well galleries should be divided in a finite number of sections $\Delta g_{j}, j=1, \ldots, J$ with a constant specific pumpage $q_{j}$. Assuming a homogeneous horizontal hydrogeological structure along the gallery, the well distance $\Delta w_{j}$ for the section $j$ will be constant and for the number of wells holds

$$
n_{w, j}=\frac{\Delta s_{j}}{\Delta w_{j}}
$$

with $\Delta s_{j}$ - length of section $\Delta g_{j}$

For a given well construction and drainage target the well distance $\Delta w_{f}$ is a multidimensional function, depending on the specific pumpage $q$, and on the hydrogeological parameter $p_{j}$ (the transmissivity) for the gallery section $j$. We assume steady state conditions.

$$
\Delta w_{j}=f_{w}\left(p_{g}, q_{g}\right)
$$


Frequently the well distance for single aquifers is estimated from the following implicit mathematical model, Luckner et al. 1969:

$$
\boldsymbol{q}_{j}=T_{j} \cdot \frac{H_{g, j}-H_{w, j}}{\frac{\Delta w_{j}}{2 \cdot \pi} \cdot \ln \frac{\Delta w_{j}}{2 \cdot \pi \cdot r_{0, j}}}
$$

with $q_{j}$ - specific pumpage for sector $j$.

$T_{j}$ - actual transmissivity for sector $j$,

$H_{g, j}$ - piecometric head at the drainage contour of sector $j$,

$H_{w, j}$-minimum piecometric head in the drainage wells,

$r_{0 . j}$ - hydraulic effective radius of the wells.

The specific pumpage is a function of the hydrogeological parameter of the subarea $\Delta \Sigma_{\mathbf{4}}$.

$$
q_{j}=f_{q}\left(p_{1}, p_{2}, \ldots, p_{N}\right)
$$

From Eq. (12), (10), (9) we would get

$$
n_{w . j}=f_{n}\left(p_{1}, p_{2}, \ldots, p_{N}\right)
$$

Such a relationship woula give us the interdependency between the reliability of the hydrogeological parameters to be explored and the design value of the drainage system. Unfortunately such a function can not be found for generalized problems. This is a consequence of the nonlinear, implicite well functions (e.g. Eq. (11)), and of the numerical solution of the groundwater flow problem. This will be discussed in the next section.

\subsection{Geohydraulic Calculation with Hypothetic Hydrogeological Models}

The specific pumpage $q_{j}, j=1, \ldots, J$ has to be estimated by the help of geohydraulic calculations. In general, for such calculations comprehensive systemdescriptive groundwater flow models are used. Analytical solutions are rarely applicable. Consequently, their is no explicit relationship between the hydrogeological parameters of the system and the specific pumpage. Furthermore, we will not get an explicite relationship between random hydrogeological parameters and random specific pumpage (both in terms of a probability distribution function or as expectation values with confidence interval).

Empirical attempts to obtain empirical distributions (and confidence intervals) have been made using Monte-Carlo simulations, e.g. Reichel 1979, or applying numerical approaches, Reichel et al. 1982. The practical applicability is restricted due to the large amount of computations needed.

In the following, we propose a reduced deterministic approach, based on the theory of statistical experiments, Scheffler 1974.

Instead of a stochastic parameter model (Section 2.1 ) a discrete lumped parameter model is used. Each parameter is described as a finite number of possible realizations, chosen by the help of statistical methods.

$$
p_{i}:\left(p_{i}^{(1)}, p_{i}^{(2)}, \ldots, p_{i}^{(b)}\right)
$$

Through simulation experiments with an appropriate groundwater flow model the effect of different realizations of the parameters - called hypothetical hydrogeological model - on the specific pumpage $q_{j}$ and finally the design value $\Delta w_{j}$ can be estimated. 
If a linear relationship between the hydrogeological parameters $p_{i}$ and the design value $\Delta w_{f}$ holds true, two step experiments are needed. Two step experiments are also reasonable as a first approximation for nonlinear relationships, see below.

Each parameter is described by its expected lower and upper bounds:

$$
\hat{p}_{i}:\left\{\overline{\min p_{i}} \mid \overline{\max p_{i}}\right\}
$$

These values may be estimated by previous hydrogeological explorations and practical experiences.

Define $m$ the number of independent parameters to be explored. Consequently, $2^{m}$ experiments with hypothetical models are needed to cover all possible combinations of parameters. This might be with one parameter in $m$ subareas or $N$ parameters in $m$ subareas with $m=N \cdot m^{*}$. Here the problem of numerical effort in case of more than $\approx 4$ parameters becomes obvious (e.g. $m=8$ results in 256 experiments).

To overcome this problem two alternatives should be investigated:

- application of simulation models with low computational effort.

- application of the theory of statistical experiments to reduce the number of experiments.

The outcome of the first alternative is restricted. In principle, the systemdescriptive groundwater flow models with distributed parameters have to be used. That means, numerical models based on Finite-Differences-Methods or FiniteElements-Methods are needed. A certain number of nodes (elements) is required to satisfy a acceptable accuracy. Furthermore, this number might increase with the number of parameters to be investigated.

In case of nonlinear relationships the deviation from the linear behavior can be estimated with an additional experiment for the central point $\left(\overline{\min p_{i}}+\overline{\max p_{i}}\right) / 2$. For strong nonlinearities more detalled computations are necessary, e.g. $3^{m}$ experiments in the case of a quadratic dependency.

From the experiments with the hypothetical models we obtain an evaluation to the effect of the hydrogeological parameter $\bar{p}_{i}$ in the subarea $i$ on the drainage design, $n_{w, j}, j=1, \ldots, J$. Obviously, the effect depends above all on the distance of the subarea from the location of the drainage system.

Define a hypothetical model $\mathbf{M}\left(\bar{p}_{i}\right)$ as a model characterized by a special parameter $\bar{p}_{i}$ for subarea $i$ and any values according to Eq. (15) for the parameters of the other subareas $l, l=1, \ldots, N ; l \neq i$.

$$
\mathbf{M}\left(\bar{p}_{i}\right)=\left\{\hat{p}_{1}, \hat{p}_{2}, \ldots, \bar{p}_{i}, \ldots, \hat{p}_{N}\right\}
$$

Analogously we define $\mathbf{M}\left(\bar{p}_{k}, \bar{p}_{k}\right)$ as

$$
\mathbf{M}\left(\bar{p}_{1}, \bar{p}_{k}\right)=\left\{\hat{p}_{1}, \hat{p}_{2}, \ldots, \bar{p}_{1}, \ldots, \bar{p}_{k}, \ldots, \hat{p}_{N}\right\}
$$

In using this notation we can define main effects and interaction effects.

The main effect $\Delta n_{w, y}^{k}$ of the parameter $\bar{p}_{i}$ is defined as the difference between the mean for all parameter combinations for $\overline{\operatorname{maxp}}$ minus the mean for all parameter combinations for $\overline{\min p_{i}}$.

$$
\Delta n_{w, j}^{\mathfrak{l}}=\Delta n_{w, j}\left(\bar{p}_{\mathfrak{l}}\right)=\frac{1}{K 1}\left[\sum_{1}^{K 1} \mathbf{M}\left(\overline{\max p_{\mathfrak{l}}}\right)-\sum_{1}^{K} \mathbf{M}\left(\overline{\min p_{\mathfrak{l}}}\right)\right]
$$


with $\quad K 1$ - number of models $\left(=2^{N-1}\right)$.

This relationship implies that the parameters of the subareas $l, l=1, \ldots, N, l \neq i$ are considered as a mean. Consequently for a linear dependency between $\Delta n_{w, j}$ and $\bar{p}_{1} \Delta n_{w, j}$ is the number of wells for section $j$ being additionally necessary if the parameter $\bar{p}_{i}$ changes from $\overline{\min p_{i}}$ to $\overline{\max p_{i}}$.

The interaction effect $\Delta n_{w, j}^{i, k}$ is defined as

$$
\begin{aligned}
\Delta n_{w, j}^{i, k}=\frac{1}{2} & \mid \frac{1}{K 2}\left[\sum_{1}^{K 2} \mathbf{M}\left(\overline{\max p_{i}}, \overline{\max p_{k}}\right)-\sum_{1}^{K 2} \mathbf{M}\left(\overline{\min p_{i}}, \overline{\max p_{k}}\right)\right\} \\
& \left.-\frac{1}{K 2}\left(\sum_{1}^{K 2} \mathbf{M}\left(\overline{\max p_{i}}, \overline{\min p_{k}}\right)-\sum_{1}^{K 2} \mathbf{M}\left(\overline{\min p_{i}}, \overline{\min p_{k}}\right)\right]\right)
\end{aligned}
$$

with $\quad K 2$ - number of models $\left(=2^{N-2}\right)$.

In the case of $3^{m}$ experiments or more a variance analysis has to be applied. The number of experiments can be reduced neglecting some of the interaction effects, see Scheffler 1984.

With Eq. (18) and (19) we have got a measure for the effect of parameter changes on the design values. As larger these main effects for the parameter $\bar{p}_{i}$ of a subarea $\Delta \Sigma_{i}$ are, as more important is the exploration in that subarea. Large interaction effects $\Delta n_{w, j}^{i, k}$ indicates, that the parameter $\bar{p}_{i}$ has a significant influence on the design with a special constellation of parameter $\bar{p}_{k}$. According to these numbers a step-wise exploration might be implemented. We will illustrate this in Section 3 for an example.

\subsection{Economic Evaluation Depending on Exploration Precision}

For the time being we will not consider the economic evaluation of the risk due to insufficient design of mine drainage, as explained above. We will base on the economic evaluation of the drainage design and of the exploration. In Figure 5 the principle economical relationships are depicted.

As lower the exploration precision is, as higher are the cost for mine drainage to be expected in order to minimize the risk of "under-design". On the other hand, the cost of exploration increases with the exploration precision.

Define ex $C_{d}$ the cost of mine drainage being necessary for the given system it means the system would have been optimal designed with exact parameters. The aciditional cost for drainage design due to insufficient exploration precision we define as hypothetical losses $L$.

To develop a relationship between the exploration precision (the number of exploration drillings) and the hypothetical losses is rather difficult. The cost for mine drainage as well as the hypothetical losses depend linear on the number of exploration drillings. But the number of drillings is a nonlinear function of the parameters, see Eq. (11).

As a first approximation we assume that the number of well drillings and consequently the hypothetical losses depend linear on the parameters $\tilde{p}_{1}, i=1, \ldots, N$. This assumption can be checked estimating the number of exploration drillings for the lower and upper parameter bounds of Eq. (15) and for the mean parameter.

Consider one parameter $\tilde{p}_{\mathfrak{r}}$ with expected lower and upper bounds $\min \tilde{p}_{i}, \max \tilde{p}_{i}$. Define $p_{i}^{d}$ its "pessimistic" value used for the design of the drainage system. Hypothetical losses due to parameter $\tilde{p}_{1}$ will equal zero, if the parameter $p_{i}^{d}$ is equal to the real value $\tilde{p}_{i}$, and will reach the maximum, if $\tilde{p}_{\mathfrak{l}}$ is equal to the "optimistic" value $p_{i}$. 


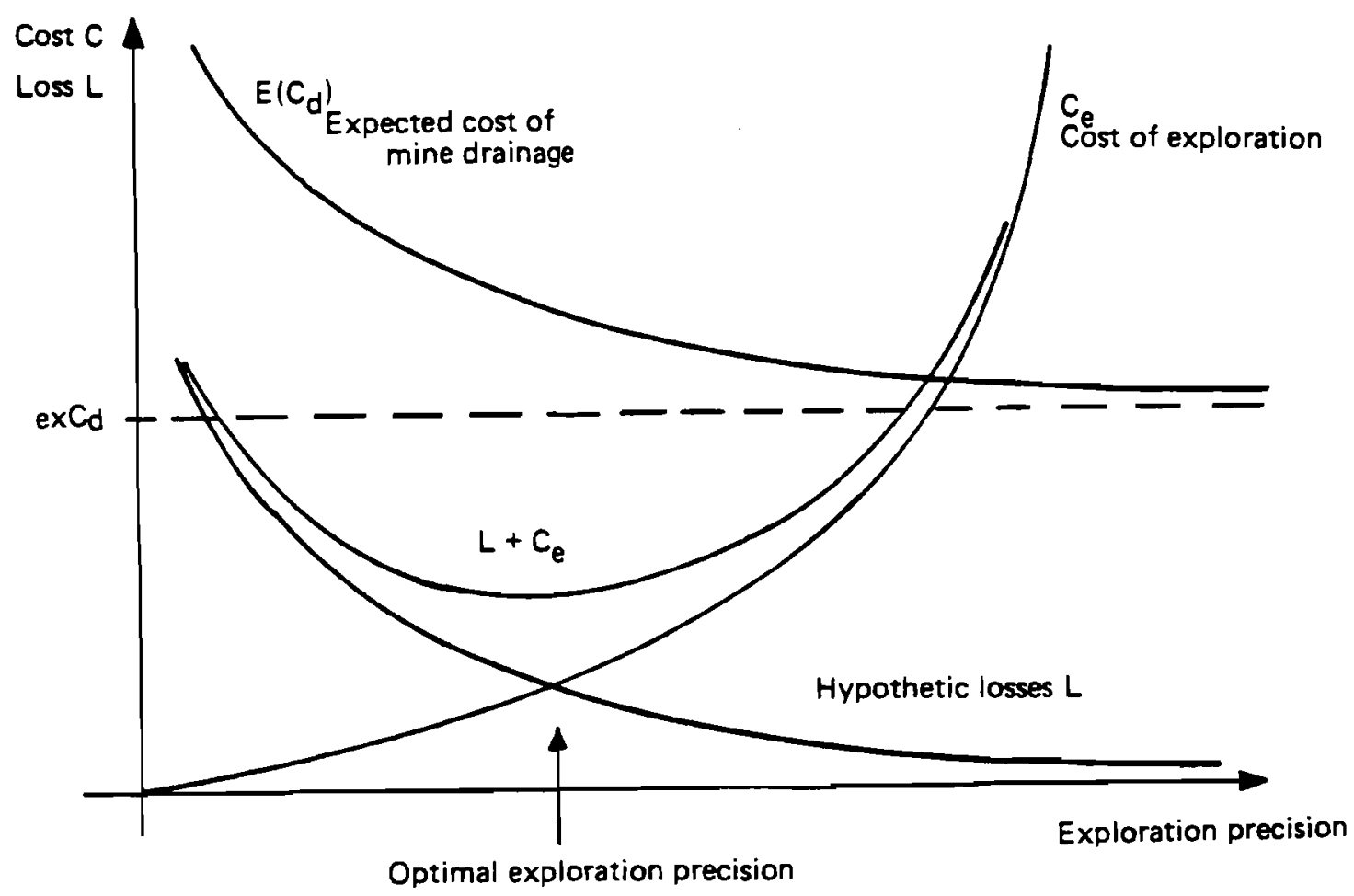

Figure 5 : Economical evaluation

The losses are defined as

$$
L\left(\tilde{p}_{i}\right)=\frac{\min C_{d}-\max C_{d}}{p_{i}^{p}-p_{i}^{d}} \cdot\left(\tilde{p}_{i}-p_{i}^{d}\right)
$$

with

$$
\begin{aligned}
& p_{i}^{d}=\min \tilde{p}_{i} \rightarrow p_{i}^{0}=\max \tilde{p}_{i} \\
& p_{i}^{d}=\max \tilde{p}_{i} \rightarrow p_{i}^{0}=\min \tilde{p}_{\mathfrak{q}}
\end{aligned}
$$

or

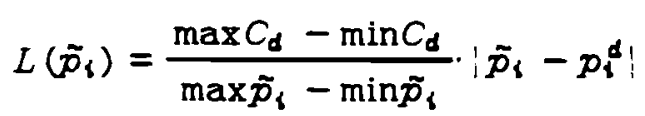

In Figure 6 the function is illustrated.

For the parameter $p_{i}^{d}$ we apply the generalized parameter model from Eq. (8).

$$
p_{i}^{d}=\bar{p}_{i} \pm \Delta \bar{p}_{i}\left(n_{b, 1}\right)
$$

That means, for the design either the lower or upper confidence limit (for a given probability) is used.

Inserting Eq. (22) into Eq. (21) we obtain

$$
L\left(\tilde{p}_{\mathfrak{i}}\right)=\frac{\max C_{d}-\min C_{d}}{\max \tilde{p}_{\mathfrak{q}}-\min \tilde{p}_{\mathfrak{q}}} \cdot\left|\tilde{p}_{\mathfrak{q}}-\bar{p}_{\mathfrak{q}}=\Delta \bar{p}_{\mathfrak{i}}\left(n_{b, 1}\right)\right|
$$




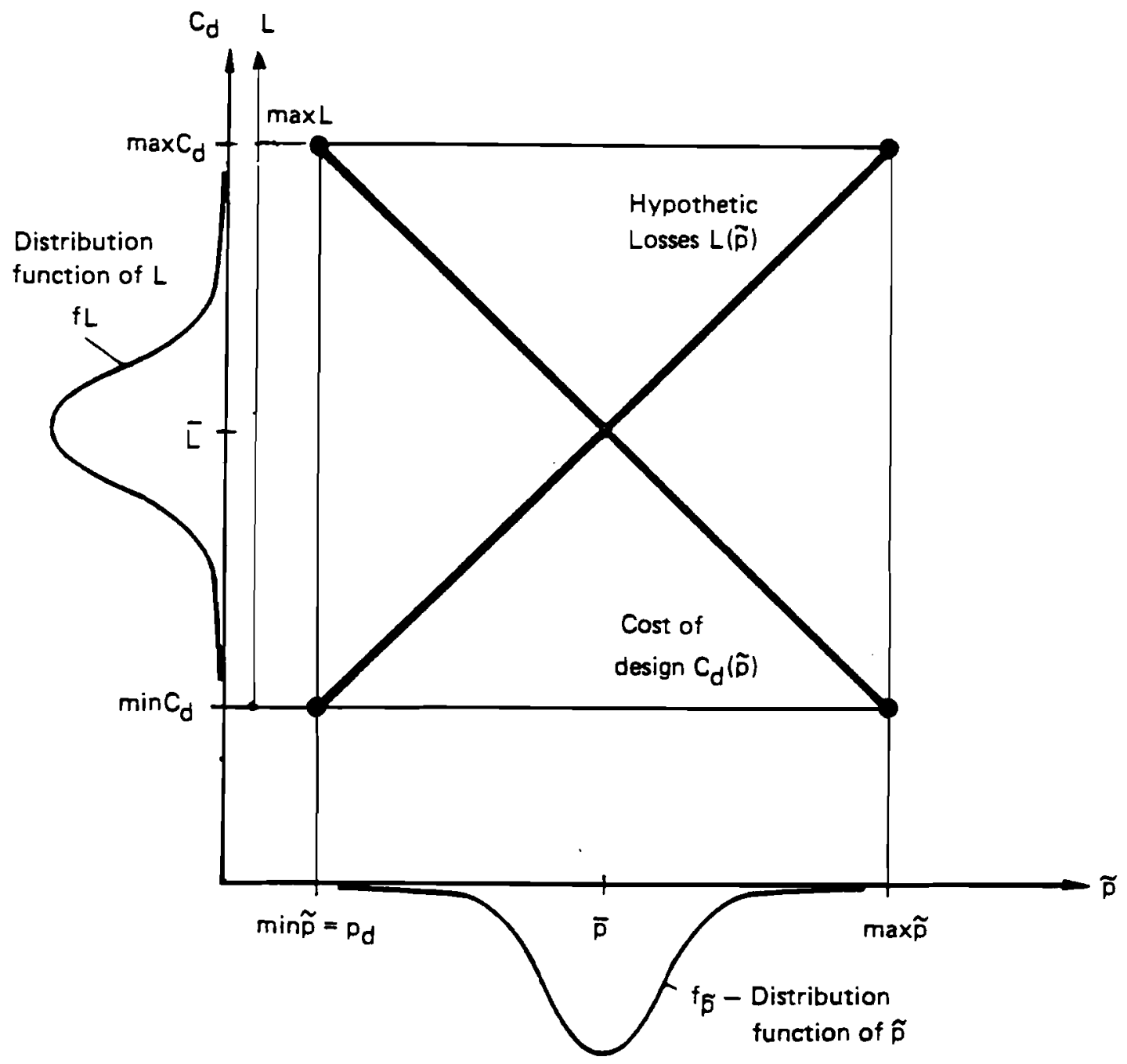

Figure 6 : Cost of design and hypothetical losses in relation to the parameter $\tilde{p}_{\imath}$ for $p_{i}^{d}=\min \tilde{p}_{i}$.

For the normal distributed parameter model we get with Eq. (7)

$$
L\left(\tilde{p}_{i}\right)=\frac{\max C_{d}-\min C_{d}}{\max \tilde{p}_{i}-\min \tilde{p}_{i}} \cdot\left|\tilde{p}_{i}-\bar{p}_{i} \pm \frac{s_{d}}{\sqrt{n_{b, t}}} \cdot t_{a, m_{4}}\right|
$$

In Figure 7 this functional relationship is illustrated.

Because $\tilde{p}_{\mathfrak{t}}$ is normal distributed, $L\left(\tilde{p}_{1}\right)$ is normal distributed with the mean

$$
E\left[L\left(\tilde{p}_{1}\right)\right]=L\left(\bar{p}_{i}\right)
$$

and the dispersion

$$
\sigma_{L}^{2}=\left(L\left(\bar{p}_{i}-\frac{s_{i}}{\sqrt{n_{b, 1}}}\right)-L\left(\bar{p}_{i}\right)\right)^{2}
$$

An open problem is the evaluation of the cost of drainage. Let $c_{w}$ be the specific cost of one drainage well. Now we will replace the cost by using the effects, being defined in the previous section (Eq. (18), (19)). 


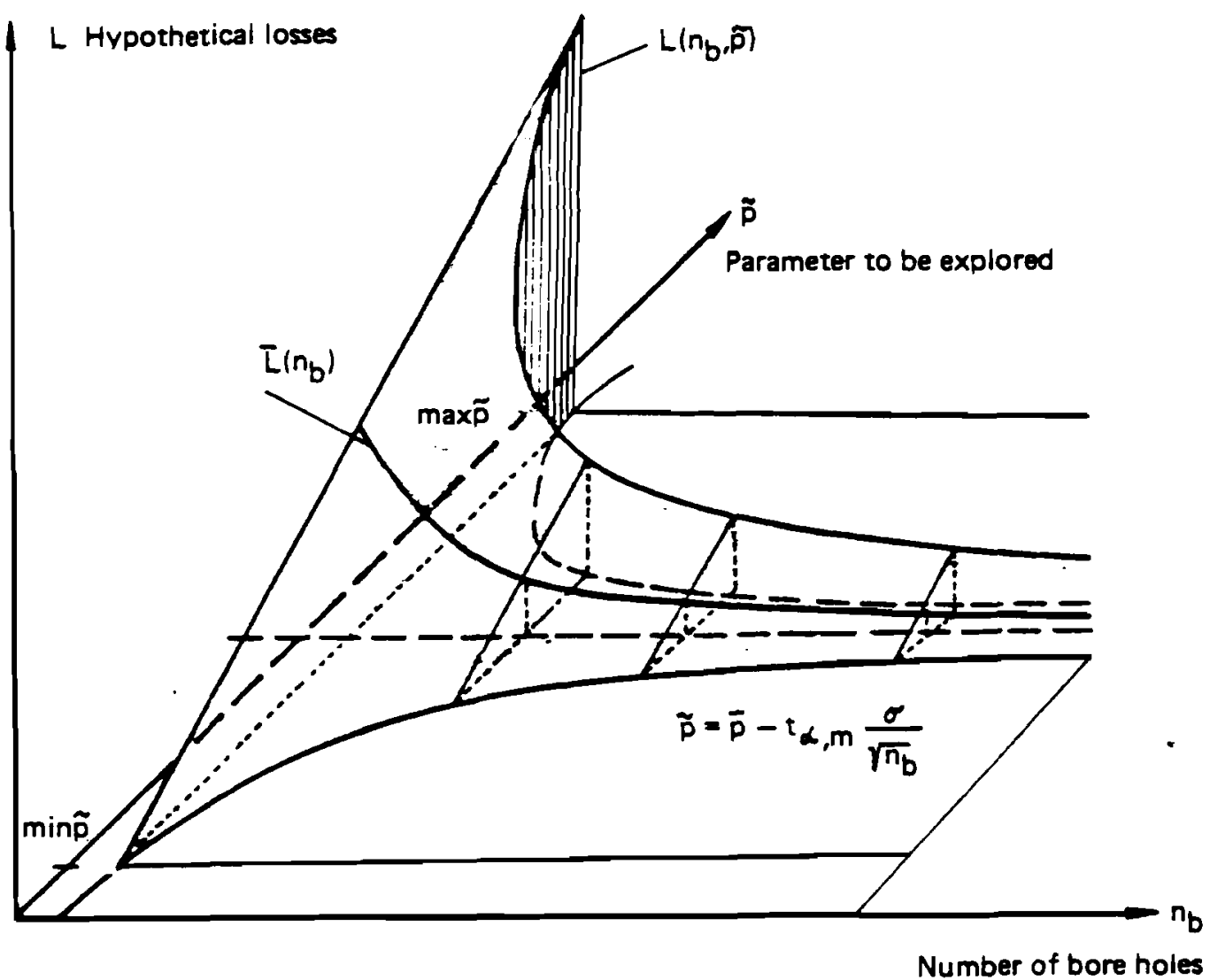

Figure 7: Hypothetical losses for normal distributed parameters

$$
\max C_{d}-\min C_{d}=\left|\Delta n_{w, j}^{q}\right| \cdot c_{w}
$$

As explained above, $\Delta n_{w, y}^{1}$ is the number of wells being additional necessary, if the parameter $\tilde{p}_{f}$ changes from min $\tilde{p}_{t}$ to $\max \tilde{p}_{f}$. - And this is the meaning of $\max C_{d}-\min C_{d}$ !

Inserting in Eq. (22) we obtain

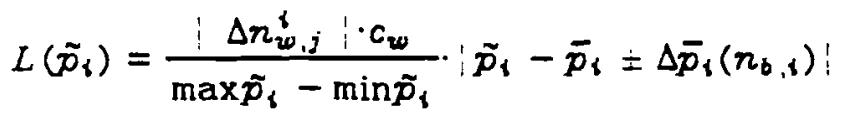

In the case of normal distributed parameters we can replace max $\tilde{p}_{i}-\min \tilde{p}_{6}$

$$
\frac{\max \tilde{p}_{i}-\min \tilde{p}_{i}}{2}=l \cdot s_{\mathfrak{i}}
$$

with $s_{\uparrow}$ - variance

$$
l \text { - measure of the quality of previous informations }
$$

Hence we get for Eq. (23) with Eq. (27)

$$
L\left(\tilde{p}_{i}\right)=\frac{\left|\Delta n_{w, j}^{q}\right| \cdot c_{w}}{2 \cdot l \cdot s_{i}} \cdot\left|\tilde{p}_{i}-\bar{p}_{i}=\frac{s_{i}}{\sqrt{n_{b, q}}} \cdot t_{a, m_{i}}\right|
$$


For the cost of exploration we assume a linear dependency on the number of bore holes. For instance, we might use the following simple expression

$$
c_{0}=C_{i, c}+c_{b} \cdot \sum_{i=1}^{N} n_{b, b}
$$

with $\quad C_{0, E}-$ constant cost of exploration

$c_{b}$ - specific cost of exploration (cost of one bore hole).

\subsection{Optimal Exploration Precision}

We obtain the optimal exploration precision in minimizing the sum of total hypothetical losses and cost of exploration. For a parallel exploration of all subareas holds:

$$
V=\sum_{i=1}^{N} L\left(\tilde{p}_{i}\right)+C_{i, c}+c_{b} \cdot \sum_{i=1}^{N} n_{b, i} \rightarrow \operatorname{Min} . !
$$

The hypothetical losses $L\left(\tilde{p}_{i}\right)$ depend on the number of exploration bore holes in the subarea $i$ only (compare Eq. (28), (29)). Consequently, the minimum problem Eq. (32) can be separated in a set of minimum problems, without consideration of $C_{i, c}$. For each subarea a part of the constant cost $C_{i, \varepsilon}$ may be added, as it is done in the example (Section 3.). But this does not change the optimal number of exploration drillings.

$$
V_{i}=L\left(\tilde{p}_{6}\right)+c_{6} \cdot n_{b, t} \rightarrow \operatorname{Min} . !, \quad i=1, \ldots, N
$$

With Eq. (28) we get

$$
\frac{\left|\Delta n_{w, j}^{1}\right| \cdot c_{w}}{\max \tilde{p}_{i}-\min \tilde{p}_{i}} \cdot\left|\tilde{p}_{i}-\bar{p}_{i} \pm \Delta \bar{p}_{i}\left(n_{b, b}\right)\right|+c_{b} \cdot n_{b, \downarrow} \rightarrow \text { Min. ! }
$$

An exploration is only then reasonable, if it leads to more precise informations in comparison with the previous informations being fixed in max $\tilde{p}_{i}, \min \tilde{p}_{i}$. For the minimum number of bore holes min $n_{b, 6}$ we obtain by using the confidence limit

$$
\Delta \bar{p}\left(\min n_{b . i}\right)=\frac{\max \tilde{p}_{i}-\min \tilde{p}_{i}}{2}
$$

From Eq. (35) minn $n_{b, 8}$ may be obtained.

Hence, Eq. (34) has to be investigated for

$$
n_{6,8}>\min n_{6,6}
$$

Eq. (34) does not describe a simple minimization problem due to the stochastic parameter $\tilde{p_{t}}$. According to Schneeweiss, 1967 the decision should be based on the minimization of expectation values (Bayes-decision). The expectation value for $\tilde{p}_{i}$ is $\bar{p}_{i}$. Hence we obtain from Eq. (34) with Eq. (25) a deterministic problem being solvable.

$$
\frac{\left|\Delta n_{w, y}^{q}\right| \cdot c_{w}}{\max \tilde{p}_{q}-\min \tilde{p}_{q}} \cdot \Delta p\left(n_{b, \ell}\right)+c_{b} \cdot n_{b, \gamma} \rightarrow \operatorname{Min.} !
$$


If the function of losses is nonlinear, the expectation value of losses might not be obtained explicitly. Then the Monte-Carlo method should be used to estimate the expectation value of losses depending on the parameter model.

Finally lets consider the case of normal distributed parameters. For the minimum number of bore holes holds

$$
t_{a, m_{i}} \cdot \frac{s_{i}}{\sqrt{\min n_{b, i}}}=\frac{\max \tilde{p}_{i}-\min \bar{p}_{i}}{2}
$$

With Eq. (29) we get

$$
\begin{gathered}
\frac{t_{a, m_{l}}}{\sqrt{\min n_{b, l}}}=\frac{l}{2} \\
\min _{b, r}=\left[2 \cdot \frac{t_{a, m_{l}}}{l}\right)^{2}
\end{gathered}
$$

$t_{a, m_{y}}$ has to be taken from tables with

$$
m_{1}=n_{b, 6}-1
$$

For $n_{b, t}>\min n_{b .1}$ we obtain from Eq. (37) and (30)

$$
f\left(n_{b, l}\right)=\frac{\Delta n_{w, j}^{1}: \cdot c_{w}}{2 \cdot l} \cdot \frac{t_{a, m_{l}}}{\sqrt{n_{b, l}}}+c_{b} \cdot n_{b, b} \rightarrow \operatorname{Min} . !
$$

Eq. (41) cannot be solved explicitely because $t_{a, m_{q}}$ depends on $n_{b, t}$ (Eq. (40)). The simplest way for the solution is to calculate the values starting from $n_{b, 1}=\min n_{6,1}$ until the minimum is reached.

To reduce the number of calculations, Eq. (41) might be solved for an estimate of $\overline{t_{a, m_{r}}}$.

$$
\overline{n_{b, l}} \approx\left(\frac{1}{8} \frac{\Delta n_{w, j}^{t^{2} \cdot c_{w}}}{l \cdot c_{b}} \cdot \overline{t_{a, m_{3}}}\right)^{\frac{3}{2}}
$$

The optimal $n_{b, 3}$ has to be determined precisely in the vicinity of $\overline{n_{b, 8}}$ with the help of Eq. (41).

\section{Test Example}

We will demonstrate the developed approach for a simplified example of the design of a mine drainage gallery. The schematized system is depicted in Figure 8. We consider a confined aquifer, schematized into 4 homogeneous subareas (with the transmissivities $\left.T_{1}, T_{2}, T_{3}, T_{4}\right)$. The variance of the real transmissivities within these subareas is expected to be small, the mean value $\bar{T}$ is approximately equal to the representative value $T_{R}$.

The well gallery has to be designed to satisfy a given groundwater depression next to the mine. Two alternatives of the location of the gallery are under consideration, as Figure 8 indicates (Example 1, Example 2). The piecometric head inside the drainage contour has to be equal $20 \mathrm{~m}$. 


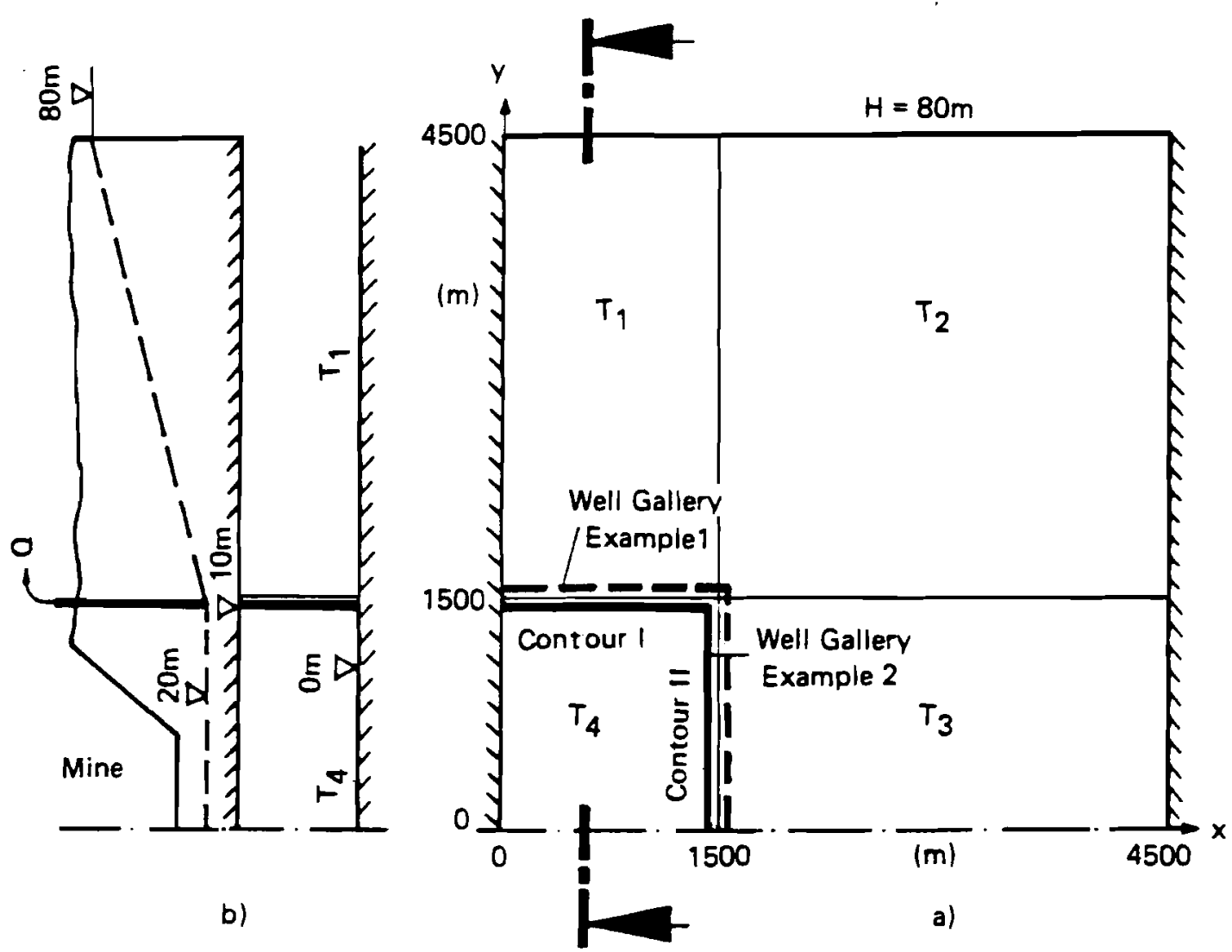

Figure 8 : Scheme of the test example, a) horizontal plan b) cross section

The transmissivities are expected to be in a given range.

$$
2.3 \cdot 10^{-4} \leq T_{1}, T_{2}, T_{3}, T_{4} \leq 2.3 \cdot 10^{-3} \mathrm{~m}^{2} / \mathrm{sec} \text {. }
$$

The drainage gallery is divided into two sections (contour $I$, contour II). For these sections a uniform distribution of the wells is assumed. For more detailed investigations the drainage contour might be divided into more sections depending on the spatial variability of the groundwater flow (compare Figure 9, below).

For the geohydraulic calculations hypothetical hydrogeological models have been composed from the minimal and maximal expected transmissivities.

$$
\begin{aligned}
& \min T_{1, \ldots, 4}=2.3 \cdot 10^{-4} \mathrm{~m}^{2} / \mathrm{sec} . \\
& \max T_{1, \ldots, 4}=2.3 \cdot 10^{-3} \quad \mathrm{~m}^{2} / \mathrm{sec} .
\end{aligned}
$$

In Table 1 the hypothetical models are listed.

For each hypothetical model the specific pumpage $q_{I}, q_{I}$ (steady state values) had to be estimated. We used a finite difference groundwater flow model, Reichel and Lomakin 1984. The computational results are independent on the parameter $T_{4}$. . That means, the results for the models $9-16$ are the same as those for the models $1-8$ (in the same order). Furthermore, the results for Example 1 and 2 are equal, assuming that the difference in the location of the gallery is negligible. 
Table 1 : Hypothetical hydrogeological models for simulation experiments

\begin{tabular}{|c|c|c|c|c|c|c|c|c|c|c|c|c|c|c|c|c|}
\hline & 1 & 2 & 3 & 4 & 5 & 6 & & & 9 & 10 & 11 & 12 & 13 & 14 & 15 & 16 \\
\hline & & & & & & & & & & & & & $\operatorname{nin}$ & & & \\
\hline & & & & & & & & & & & & & & & & \\
\hline & $\min$ & & $\min$ & & & & & & & $\min$ & $\min$ & $\min$ & $\max$ & $\max$ & $\max$ & $\max$ \\
\hline & $\min$ & $\min$ & $\min$ & $\min$ & $\min$ & $\min$ & $\min$ & $\min$ & & $\max$ & $\max$ & $\operatorname{nax}$ & $\max$ & $\max$ & $\max$ & \\
\hline
\end{tabular}

The computational result for the 8 experiments are illustrated in Figure 9. The specific pumpage was normalized by the maximum piecometric difference $\Delta H=60 \mathrm{~m}$.

For drainage contour I the maximum pumpage appertains to model 4 ( maximum values for $T_{1}, T_{2}$ ). As expected for contour II the maximum pumpage is reached for the models 7 and 8 (maximum values of $T_{2}, T_{3}$ ). The larger the pumpage is, the larger becomes its dependency on space.

Based on Eq. (11) and on mean values of the specific pumpage for the drainage contours I and II from the simulation experiments (Figure 9) the optimal well distance has been estimated using the following data:

$$
\begin{gathered}
H_{c}=20 \mathrm{~m} \quad H_{w}=10 \mathrm{~m} \quad T_{0}=0.35 \mathrm{~m} \\
\text { Example 1 : } T_{w, I}=T_{1}, T_{w, I}=T_{3} \\
\text { Example 2: } \quad T_{w, I}=T_{w, I}=T_{4}
\end{gathered}
$$

The optimal number of wells is

$$
n_{w}=n_{w, I}+n_{w, I}=\frac{B_{I}}{\Delta w_{I}}+\frac{B_{I}}{\Delta w_{I}}
$$

with

$$
\begin{array}{ll}
B_{I, U} & \text { - length of drainage contour }(1500 \mathrm{~m}) \\
\Delta w_{l, I} & \text { - optimal well distance }
\end{array}
$$

In Table 2 the results are summerized.

Based on $\overline{\mathrm{Z}}$ q. (18) and (19) the effects of the parameters $T_{1, \ldots 4}$ on the design parameter $n_{w 0}$ have been estimated. In Table 3 selected results are listed.

For our example we assume $l=3$ and $a=0.001$ as well as $a=0.01$. The specific cost are $c_{w}=1.0$ and $c_{b}=0.2$.

From Eq. (39) and (40) we obtain the minimum number of bore holes for $T_{4}$. The calculations are given in Table 4 . The further calculations will be demonstrated for Example 2, subarea $4\left(T_{4}\right)$ with $a=0.01$.

The optimal value of $n_{6,4}$ is estimated based on Eq. (41) with $\left|\Delta n_{w 0}^{4}\right|=13.375$.

$$
f\left(n_{0,4}\right)=\frac{13.375 \cdot 1.0}{2 \cdot 3} \cdot \frac{t_{a . m_{4}}}{\sqrt{n_{w}^{4}}}+0.2 \cdot n_{w}^{4}+0.5 \Rightarrow \text { Min. }
$$

with $a=0.01$. In Table 5 the results are depicted.

Table 6 shows the results for all subareas in the case of exploration in one step. 


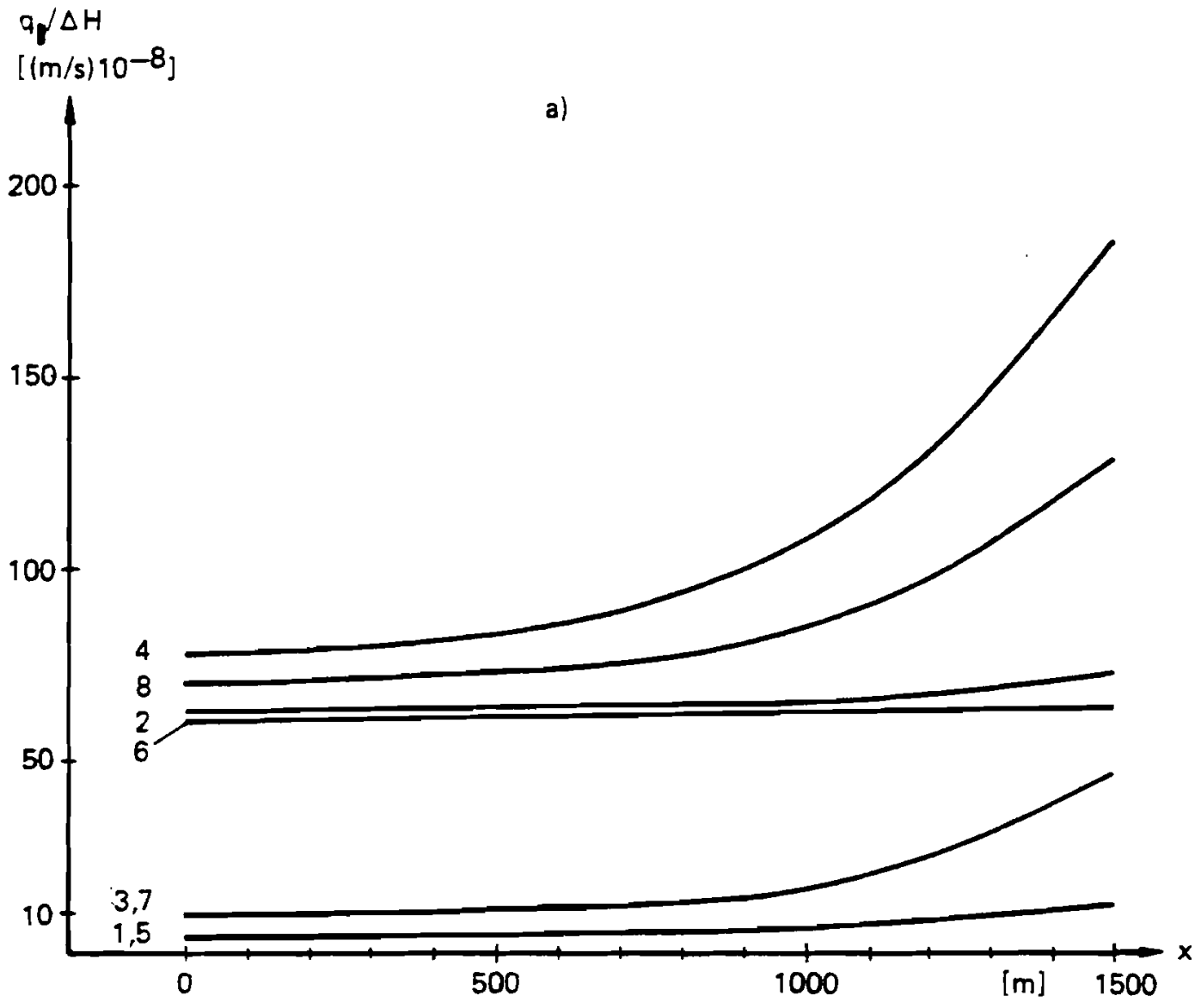

$q_{11} / \Delta H$

[(m/s) $10^{-8}$ ]

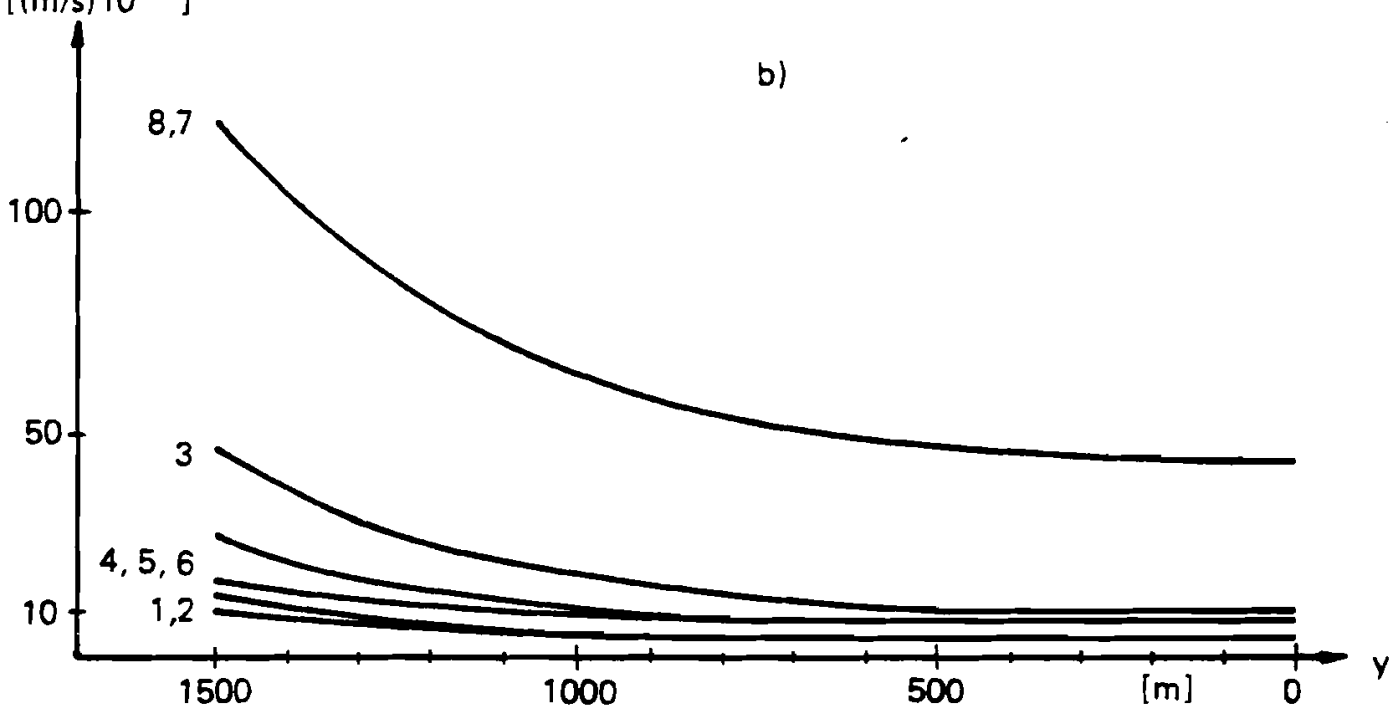

Figure 9: $\quad$ Specific pumpage for hypothetical models

a) contour I b) contour II 
Table 2 : Drainage design for the hypothetical models

\begin{tabular}{|l|c|c|c|c|c|c|c|c|c|c|c|c|c|c|c|c|c|}
\hline \multicolumn{2}{|c|}{ Number } & 1 & 2 & 3 & 4 & 5 & 6 & 7 & 8 & 9 & 10 & 11 & 12 & 13 & 14 & 15 & 16 \\
\hline \hline Ex. & $n_{w . I}$ & 3 & 3 & 6 & 4 & 3 & 3 & 6 & 3 & & & & & & & & \\
1 & $n_{w, U}$ & 3 & 3 & 9 & 5 & 1 & 1 & 3 & 3 & & & & & & & & \\
& $n_{w}$ & 6 & 6 & 15 & 9 & 4 & 4 & 9 & 6 & & & & & & & & \\
\hline \hline Ex. & $n_{w . I}$ & 3 & 14 & 6 & 20 & 3 & 15 & 6 & 17 & 1 & 3 & 1 & 4 & 1 & 3 & 1 & 3 \\
2 & $n_{w, I}$ & 3 & 2 & 5 & 4 & 4 & 4 & 15 & 15 & 1 & 1 & 1 & 1 & 1 & 1 & 3 & 3 \\
& $n_{w}$ & 6 & 16 & 11 & 24 & 7 & 19 & 21 & 32 & 2 & 4 & 2 & 5 & 2 & 4 & 4 & 6 \\
\hline
\end{tabular}

Table $3:$ Effects of the parameters $T_{1, \ldots, 4}$ on the design parameter $n_{w}$

a) Main effects

\begin{tabular}{|l|c|c|c|c|c|c|}
\hline & & $\bar{n}_{w}$ & $\Delta n_{w}^{1}$ & $\Delta n_{w}^{2}$ & $\Delta n_{w}^{\mathrm{s}}$ & $\Delta n_{w}^{4}$ \\
\hline \hline Ex. & $n_{w, I}$ & 6.31 & 7.125 & 3.750 & -0.375 & -8.375 \\
1 & $n_{w, I}$ & 4.00 & -0.250 & 1.875 & 3.500 & -5.000 \\
& $n_{w}$ & 10.31 & 6.875 & 5.625 & 3.125 & -13.375 \\
\hline \hline Ex. & $n_{w, I}$ & 3.88 & -1.25 & 1.75 & -0.25 & \\
2 & $n_{w, I}$ & 3.50 & -1.00 & 2.50 & -3.00 & \\
& $n_{w}$ & 7.38 & -2.25 & 4.25 & -3.25 & \\
\hline
\end{tabular}

e.g. $\Delta n_{w}{ }_{w}=\frac{1}{8}(16+24+19+32+4+5+4+6)-(6+11+7+21+2+2+2+4)=6.875$

b) Interaction effects

\begin{tabular}{|l|c|c|c|c|c|c|c|}
\hline & & $\Delta n_{w}^{1,2}$ & $\Delta n_{w}^{1, \mathrm{~s}}$ & $\Delta n_{w}^{1,4}$ & $\Delta n_{w}^{2.3}$ & $\Delta n_{w}^{2,4}$ & $\Delta n_{w}^{3,4}$ \\
\hline \hline Ex. & $n_{w, I}$ & -1.25 & -0.25 & & -0.50 & & \\
1 & $n_{w, U}$ & -1.00 & -1.00 & & -1.50 & & \\
& $n_{w}$ & -2.25 & -1.25 & & -2.00 & & \\
\hline \hline Ex. & $n_{w, I}$ & 0.375 & -0.375 & -4.875 & -0.625 & -1.625 & 0.125 \\
2 & $n_{w, U}$ & 0.000 & 0.250 & 0.250 & 2.750 & -2.750 & -2.500 \\
& $n_{w}$ & 0.375 & -0.125 & -4.625 & 2.125 & -4.375 & -2.375 \\
\hline
\end{tabular}

e.g. $\Delta n_{w}^{1,2}=\frac{1}{2}\left(\frac{1}{4}(24+32+5+6-11-21-2-4) \frac{1}{4}(16+19+4+4-6-7-2-2)\right)$

$$
\Delta n_{w}^{1.2}=\frac{1}{2}(7.25-6.50)=0.375
$$

Finally some thoughts on the estimation of exploration profitability by the help of the calculated effects (Table 3 ).

If we arrange the effects according to their values for $n_{w}$ (Table 7 ), we get a general impression of the importance of different subareas for exploration.

For exampie 1 the exploration profitability decreases in the sequence $T_{2}, T_{3}, T_{1}$. The values are in the same range and the interaction effects are small. Consequently for Example 1 the subareas couid be explored together. 
Table 4: Calculation of the minimum number of bore holes

\begin{tabular}{|c|l|c|c|c|}
\hline$n b 4$ & $t_{0.01, m_{r}}$ & {$\left[2 \cdot \frac{t_{0.01, m_{4}}}{3}\right]^{2}$} & $t_{0.001, m_{4}}$ & {$\left[2 . \frac{t_{0.001, m_{4}}}{3}\right]^{2}$} \\
\hline 5 & 3.75 & 6.25 & & \\
6 & 3.37 & $\frac{5.05}{7}$ & & \\
\hline 7 & 3.14 & 4.38 & & \\
8 & 3.0 & & 4.79 & 11.06 \\
9 & 2.90 & & 4.50 & $\frac{9.0}{10}$ \\
2.82 & & 4.30 & 8.22 \\
11 & 2.76 & & 4.14 & 7.62 \\
\hline
\end{tabular}

$a=0.01 \rightarrow \min n_{i}=6: a=0.001 \rightarrow \min n_{b, i}=9$

The optimal value of $\mathrm{nb}_{4}$ is estimated based on Eq. (41) with $\left|\Delta \boldsymbol{n}_{\boldsymbol{w}}\right|=13.375$.

Table 5: Calculation of the optimal number of bore holes for $T_{4}$

\begin{tabular}{|c|c|c|c|}
\hline$n_{t, 4}$ & $m_{4}$ & $t_{a, m_{4}}$ & $f\left(n_{b, 4}\right)$ \\
\hline 7 & 6 & 3.14 & 4.5 \\
8 & 7 & 3.0 & 4.46 \\
9 & 8 & 2.9 & 4.445 \\
\hline 10 & 9 & 2.82 & 4.48 \\
11 & 10 & 2.76 & 4.57 \\
\hline
\end{tabular}

Table 6: Optimal number of bore holes for all subareas

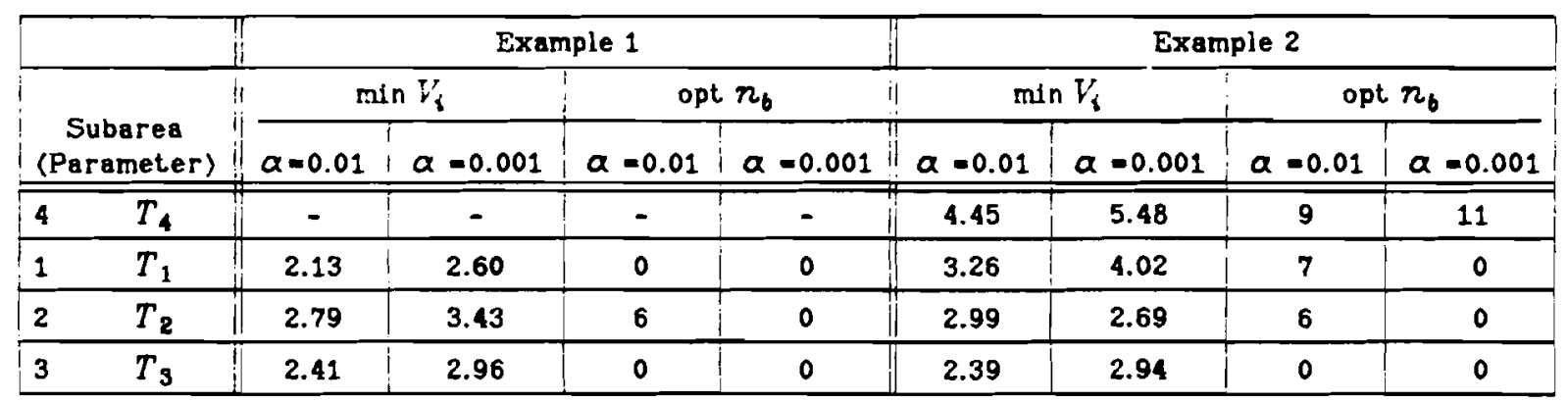

In Example 2 the main effect decrease from $T_{4}, T_{1}, T_{2}$ up to $T_{3}$. Both, the high main effect for $T_{4}$, and the high interaction effects for $T_{1}, T_{2}$ indicates that subarea 4 should be explored first. This also becomes obvious looking at Table 6. After that should be decided on the exploration of the other subareas.

In the case of step-wise exploration, the computed results for the hypothetical models (e.g. Figure 9) could be interpolated for the estimated parameter for the first explored subarea. The next working steps remain the same as before - with reduced number of hypothetical models. 
Table 7 : Selection of main effects and interaction effects

\begin{tabular}{|c|c|c|c|c|c|}
\hline \multicolumn{4}{|c|}{ Nain effects } & \multicolumn{2}{|c|}{ Interaction effects } \\
\hline $\begin{array}{l}\text { Ex. } \\
1\end{array}$ & $\begin{array}{l}T_{2} \\
T_{3} \\
T_{1}\end{array}$ & $\begin{array}{l}\Delta n_{w}^{2} \\
\Delta n_{w}^{3} \\
\Delta n_{w 0}^{1}\end{array}$ & $\begin{array}{r}4.17 \\
-3.25 \\
-2.25\end{array}$ & $\begin{array}{l}\Delta n_{w}^{2, s} \\
\Delta n_{w}^{1,2} \\
\Delta n_{w}^{1 . s}\end{array}$ & $\begin{array}{l}-2.00 \\
-2.25 \\
-1.25\end{array}$ \\
\hline $\begin{array}{l}E x . \\
2\end{array}$ & $\begin{array}{l}T_{4} \\
T_{1} \\
T_{2} \\
T_{3}\end{array}$ & $\begin{array}{l}\Delta n_{w}^{4} \\
\Delta n_{w w}^{1} \\
\Delta n_{w}^{2} \\
\Delta n_{w}^{3}\end{array}$ & $\begin{array}{c}-13.375 \\
6.875 \\
5.625 \\
\\
3.125\end{array}$ & $\begin{array}{l}\Delta n_{w}^{1,4} \\
\Delta n_{w, 4}^{2,4} \\
\Delta n_{w}^{2,1} \\
\Delta n_{w, 4}^{3,4} \\
\Delta n_{w 0}^{3,1} \\
\Delta n_{w 0}^{3,2}\end{array}$ & $\begin{array}{c}-4.625 \\
-4.375 \\
0.375 \\
-2.375 \\
-0.125 \\
2.125\end{array}$ \\
\hline
\end{tabular}

\section{Concluding Remarks}

The proposed approach is an attempt to objectify the decision process in designing exploration programs. Based on calculations with hypothetical hydrogeological model the precision of planned exploration is economically evaluated.

The optimal exploration precision (number of research drillings) is estimated by minimizing the sum of cost of exploration and hypothetical losses, depending on the exploration precision. Although the method has been described with special regard to mine drainage systems the approach is applicable to other problems too, e.g. for the exploration for groundwater extraction (water work), for environmental protection measures needed due to mine drainage, etc. In general the hypothetical losses of all activities depending on exploration precision have to be summarized.

The profitability of the exploration may be estimated, as a basis for step-wise exploration.

The demonstrated approach can be used for different parameter models, if the relationship between amount and precision of exploration can be quantified. The method is applicable for different goals of exploration, if the economic effect of the exploration can be quantified.

Further research should be concentrated on the analysis of more complicated parameter models and nonlinear economic functions. Another important task is the integration of the presented approach in complex model systems, as the system for analysis of water policies in open-pit lignite mining areas, under development at the Institute for Applied Systems Analysis, Kaden et al. 1985. 


\section{REFERENCES}

Bamberg, H.-F., Stoyan, D., and Garling, F. (1975). Beitrag zur Ermittlung der erforderlichen Erkundungs- und Erschliessungsarbeiten (Contribution to the estimation of the number of required bore holes for hydro geologic exploration and drilling), Berlin, Wasserwirtschaft/Wassertechnik, Vol.25, No.? , pp. 57-59.

Beims, U., and Luckner, L. (1974). Grundlagen der Ermittlung representativer Durchlaessigkeitsparameter (Contribution to the estimation of representative transmissivities). Berlin, Zeitschrift fuer Angewandte Geologie, Vol.20, No.7, pp. 304-313.

Goidbecher, K., and Eckardt, G. (1982). Zur Modellierung von Lagerstaetten fluider Rohstoffe (About modelling of fluid resources deposits). Berlin, Zeitschrift fuer Angewandte Geologie, Vol.28, No.1, pp. 1-6.

Kaden, S., and Luckner, L. (1984). Groundwater management in open-pit lignite mining areas. Intern. Symposium on Groundwater Resources Utilization, Montreal, Carada, May 21-23,1984, Vol.I, pp.69-78.

Kaden, S. et al. (1985). Analysis of regional water policies in open-pit lignite mining areas.Laxenburg, Austria, IIASA WP 85-04, $67 \mathrm{p}$.

Luckner, L., Peukert, D., and Loeffler, H. (1969). Beitrag zur Berechnung des durch Sickergraeben, Brunnenreihen oder Draenleitungen gewinnbaren Infiltrates aus Oberflaechengewaessern (Contribution to the estimation of the infiltrate from ditches, well galleries and drains). Berlin, Wasserwirtschaft/Wassertechnik, Vol.19, No.5, pp. 168-174.

Reichel, F. et al. (1982). Geohydraulic Computation for Open-Cast Mine Dewatering. 1.st Congress of the IMWA, Budapest, 1982, Proceedings A, pp. 246-259.

Reichel, F. (1979). Beitrag zur stochastischen Simulation der horizontal-ebenen Grundwasserströmung unter besonderer Berücksichtigung von Belangen der Projektierung für die Entwässerung (Contribution to the stochastic simulation of horizontal plane groundwater flow with special regard to mine drainage 
design). Dresden, Dissertation, Technical University.

Reichel, F. and Lomakin, J.A. (1984). Ermittlung des erforderlichen Auf wandes der hydrogeologischen Erkundung in Bergbaugebieten auf der Grundllage hypothetischer hydrogeologischer Modelle (Estimation of the required amount in the hydrogeological exploration in mining areas on the basis of hypothetical hydrogeological models). Leipzig, Neue Bergbautechnik, Vol.14, No.1, pp. 15-17.

Reisner, H. and Rösch, L. (1984). Entwicklungstendenzen der Tagebauentwässerung im Braunkohlenbergbau (Trends in open-pit mine drainage in lignite mining). Leipzig, Neue Bergbautechnik, Vol.14, No.7, pp. 260-261.

Scheffler, E. (1974). Einfuehrung in die Praxis der statistischen Versuchsplanung (Introduction in the practice of statistical design of experiments). VEB Deutscher Verlag fuer Grundstof findustrie, Leipzig.

Schneeweiss, H. (1967). Entscheidungskriterien bei Risiko (Decision criterias under risk). Springer-Verlag, Berlin, Heidelberg, New-York.

Virdee, T. S., and Kottegoda, N.,T. (1984). A brief review of kriging and its application to optimal interpolation and observation well selection. Hydrological Sciences Journal, Vol.29, No.4, pp. 367-387.

n.n. (1976). Methodik zur Erkundung von Braunkohlenlagerstätten (Methods for exploration of lignite deposits). VEB Geol. Forschung und Erkundung. Halle. GDR. 